\title{
Arginine Vasotocin in Ovine Fetal Blood, Urine, and Amniotic Fluid
}

\author{
M. Gore Ervin, Rosemary D. Leake, Michael G. Ross, Glenda C. Calvario, and Delbert A. Fisher \\ Perinatal Research Laboratories, Harbor-UCLA Medical Center, UCLA School of Medicine, Torrance, California 90509
}

\begin{abstract}
Arginine vasotocin ([8-arginine]-oxytocin) (AVT), the primary antidiuretic principle in submammalian vertebrates, has been reported to be present in mammalian pituitary and pineal glands. Although the most phyletically ubiquitous of the known neurohypophysial peptides, AVT is still not recognized as a mammalian hormone. We examined plasma, urine, and amniotic fluid from fetal lambs by radioimmunoassay (RIA) for evidence of AVT to assess the possibility of its being such a hormone. Measureable quantities of AVT-like immunoreactivity (irAVT) were observed in fetal plasma $(2.4 \pm 0.2 \mathrm{pg} / \mathrm{ml})$, urine $(1.4 \pm 0.2$ $\mathrm{pg} / \mathrm{ml})$, and amniotic fluid $(1.9 \pm 0.2 \mathrm{pg} / \mathrm{ml})$. Since the AVT antiserum shows minimal cross-reactivity with arginine vasopressin (AVP) and oxytocin (OT), measurements of AVP and OT concentrations in the same biological fluids also were conducted with specific antisera. The results suggest that the irAVT was not accountable on the basis of cross-reaction. To further verify the identity of the irAVT, a high pressure liquid chromatography system using RIA as a means of detection was developed. This system is sufficiently sensitive to allow the separation and quantitation of picogram quantities of the synthetic peptides AVT, AVP, and OT. In this system, the irAVT in fetal plasma, urine, and amniotic fluid appeared as a single peak coeluting with synthetic AVT. These results indicate that AVT is present in ovine fetal plasma and support the view that the fetus secretes this peptide. The physiological significance of circulating AVT remains to be defined.
\end{abstract}

\section{Introduction}

The neurohypophysial hormone family is comprised of 11 known structural variants, with arginine vasopressin (AVP) ${ }^{1}$ and oxytocin (OT) representing the primary nonapeptides in mammals (1). The neurohypophyses of suiforms contain the AVP analogue [8-lysine]-vasopressin (LVP), in addition to OT and in some species also AVP (2), while the marsupials exhibit

This study was presented in part at the 68th Annual Meeting of the Federation of American Societies for Experimental Biology, April 1984.

Address reprint requests to Dr. Ervin, Bldg. A-17 Annex, 1000 West Carson St., Torrance, CA 90509.

Received for publication 14 May 1984 and in revised form 22 January 1985.

1. Abbreviations used in this paper: AVP, arginine vasopressin; AVT, arginine vasotocin ([8-arginine]-oxytocin); AVP-Ab, antiserum R-357; AVT-Ab, antiserum R-4; HPLC, high pressure liquid chromatography; irAVT, AVT-like immunoreactivity; IT, isotocin ([4-serine,8-isoleucine]oxytocin); LVP, [8-lysine]-vasopressin; LVT, [8-lysine]-vasotocin; MT, mesotocin ([8-isoleucine]-oxytocin); OT, oxytocin; OT-Ab, antiserum R-421; RIA, radioimmunoassay; TFA, trifluoroacetic acid.

J. Clin. Invest.

(c) The American Society for Clinical Investigation, Inc.

0021-9738/85/05/1696/06 \$1.00

Volume 75, May 1985, 1696-1701 both LVP and the recently described analogue phenypressin ([2-phenylalanine]-arginine-vasopressin) (3). Arginine vasotocin (AVT; [8-arginine]-oxytocin), the most ubiquitous neurohypophysial principle in submammalian vertebrates, has been reported in fetal pituitary and pineal glands and/or adult pineal glands of a variety of mammalian species (4-9). However, the mammalian occurrence of AVT is still not universally accepted $(10,11)$, and AVT has not been reported in mammalian circulation.

Previous reports identifying mammalian AVT have relied on a variety of quasispecific methods, including bioassay (7), differential radioimmunoassay (RIA) (9), and immunocytochemistry (6). Because AVT is a structural hybrid of AVP and OT, i.e., there is only one amino acid difference between AVT and AVP or between AVT and OT, these methods may be compromised by significant cross-reactions. Several investigators have attempted to circumvent this problem by using separate antisera developed against AVT, AVP, and OT (10, 12, 13). Even in these elaborate RIA systems, however, the antisera specificities were not sufficient to eliminate the possibility of cross-reaction between the AVT antiserum and native AVP or OT. Thus RIA methods alone have not proved sufficiently specific to provide definitive identification of AVT in mammalian tissues, and native AVT has not been reported in mammalian blood.

We have developed a high pressure liquid chromatography (HPLC) system using RIA with three specific antisera (AVT, AVP, and OT) as a means of detection. Because the specificity of each of the antisera has been extensively characterized, this coupled HPLC-RIA system has proved sufficiently sensitive and specific to afford the separation and quantitation of picogram quantities of AVT, AVP, and OT. In the present study we applied this system to examine ovine fetal plasma, urine, and amniotic fluid for evidence of native AVT.

\section{Methods}

Peptides. Synthetic AVP, AVT, and OT were obtained from Bachem (Torrance, CA) and used as substrates for radioiodination and as standards for both the RIA and HPLC analyses. The synthetic analogues mesotocin (MT; [8-isoleucine]-oxytocin), isotocin (IT; [4-serine, 8isoleucine]-oxytocin), LVP, and [8-lysine]-vasotocin (LVT) also were obtained from Bachem for use in antisera cross-reactivity studies.

Radioiodination. Synthetic AVP, AVT, and OT were iodinated with iodogen (1,3,4,6-tetrachloro-3 $\alpha, 6 \alpha$-diphenyl glycouril; Pierce Chemical Co., Rockford, Il). The peptides were dissolved in $0.05 \mathrm{M}$ acetic acid $(1 \mathrm{mg} / \mathrm{ml})$ and $10 \mu \mathrm{l}$ of the solution was added to a $12 \times 75 \mathrm{~mm}$ borosilicate glass tube containing $1 \mu \mathrm{g}$ of iodogen and $50 \mu \mathrm{l}$ of $0.1 \mathrm{M}$ phosphate buffer. The reaction was initiated by adding $500 \mu \mathrm{Ci}$ (diluted up to $5 \mu \mathrm{l}$ in phosphate buffer) carrier-free $\mathrm{Na}^{125} \mathrm{I}$ (>300 mCi/ml; ICN Pharmaceuticals, Inc., Irvine, CA) and allowed to proceed with gentle $(5 \mathrm{~s})$ agitation every $30 \mathrm{~s}$ for $6 \mathrm{~min}$. The reaction was terminated by addition of $400 \mu \mathrm{l}$ of ice-cold buffer and subsequent aspiration of the reaction mixture.

Monoiodinated AVP and AVT were purified by CM-Sephadex chromatography as previously described (14). Freshly iodinated OT was layered onto the top of a $10 \times 100 \mathrm{~cm}$ SP-Sephadex column (C- 
25; Sigma Chemical Co., St. Louis, MO) and eluted with $0.6 \mathrm{M}$ acetate buffer, pH 4.0 (15).

Radioimmunoassay. The three antisera used were prepared in New Zealand white rabbits against synthetic peptides conjugated to bovine thyroglobulin as previously described (16). Although the three antisera have been independently described previously (R-357 [17], R-421 [15], and $R-4$ [18]), we reexamined cross-reactivity for the synthetic standards used in the HPLC analysis (AVT, AVP, and OT) and for the analogues MT, IT, LVP, and LVT. Comparisons between peptides were made by assessing the ratio of the dose of test hormone yielding $50 \%$ displacement of labeled ligand $\left(B_{50}\right)$.

AVT immunoreactivity was measured with antiserum R-4 (AVT$\mathrm{Ab}$ ) at a final dilution of 1:70,000. At this dilution, the assay detection limit was $0.10 \mathrm{pg} /$ tube; $50 \%$ displacement of labeled ligand was produced by $0.46 \mathrm{pg}$ synthetic AVT standard. For AVP determinations, antiserum R-357 (AVP-Ab) was used at a final dilution of 1:1,000,000. The assay detection limit was $0.25 \mathrm{pg} /$ tube; labeled ligand was $50 \%$ displaceable by $1.15 \mathrm{pg}$ AVP standard. Antiserum R-421 (OT-Ab) at a final dilution of 1:50,000 was used in the determination of OT immunoreactivity. The detection limit of the assay was $0.48 \mathrm{pg} /$ tube; labeled ligand was $50 \%$ displaceable by 2.97 pg synthetic OT.

For the RIA procedures, synthetic AVT, AVP, and OT were dissolved in $0.5 \%$ chlorobutanol and $0.05 \mathrm{M}$ acetic acid to yield $1 \mathrm{mg} /$ $\mathrm{ml}$ stock solutions. RIA standards were prepared by serial dilutions in assay buffer $(0.15 \mathrm{M}$ phosphate buffer, $\mathrm{pH} 7.4$, with $0.1 \%$ sodium azide and $0.25 \%$ normal rabbit serum) and the assay performed as described by Skowsky et al. (19), with one of the antisera. The synthetic analogues MT, IT, LVP, and LVT were prepared in a similar manner and assayed over a range of $0.1-10,000 \mathrm{pg} /$ tube.

Extraction of plasma for $A V P, O T$, and $A V T$. Individual plasma samples for AVP determinations were extracted with bentonite, with a mean recovery of $65.2 \%$ (19). Plasma for OT assay was extracted by an acetone-ether method as described previously (15). For the measurement of AVT levels, plasma was extracted with Sep-Pak columns ( $\mathrm{C}^{18}$-Bondapac; Waters Associates, Millipore Corp., Milford, MA) as described earlier (20). AVP and OT extracts and AVT eluates were dried in a Speedvac concentrator (model SVC-200; Savant Instruments, Inc., Hicksville, NY) and stored frozen at $-20^{\circ} \mathrm{C}$ until assayed by RIA.

The recovery of AVT was determined by the addition of $5,10,50$, or $100 \mathrm{pg}$ synthetic AVT to $1-\mathrm{ml}$ aliquots of charcoal-washed plasma pools. Plasma for these studies was obtained from either a single waterloaded human female subject or a well-hydrated, nonpregnant ewe. The recovery of standard AVT added to either fetal urine or amniotic fluid consistently exceeded $85 \%$, so these fluids were assayed directly without extraction.

Animals and surgery. A total of 18 pregnant Ramboullet-Columbia cross-bred ewes were studied, 16 with singleton fetuses and 2 with twins. Animals were housed indoors in steel study cages and maintained under a controlled lighting regimen of $12 \mathrm{~h}$ light and $12 \mathrm{~h}$ dark. Animals received both food and water ad libitum, except for the 2436-h period immediately before surgery.

Initially, eight ewes with chronic indwelling fetal vascular and amniotic fluid catheters were used as a source of fetal plasma and amniotic fluid for basal AVT, AVP, and OT immunoreactivity determinations. The surgical procedure for fetal catheter placement and the sampling methods have been described in detail (21). The mean \pm SEM gestational age of these animals at the time of sampling was $126 \pm 2 \mathrm{~d}$.

Because of the limited quantity of plasma available from the first eight animals, a large pool of fetal plasma for analysis by HPLC was obtained from three singleton and two twin fetus pairs at $130 \mathrm{~d}$ gestation. With the ewes under spinal anesthesia, lambs were delivered by cesarean section. A single polyethylene catheter was threaded to the fetal abdominal aorta before cutting of the umbilical cord, and 60-90 $\mathrm{ml}$ of whole blood was withdrawn from each animal. Blood was collected into chilled beakers containing $10 \mu l$ of $15 \% \mathrm{~K}_{2}$ EDTA per milliliter of blood. Plasma was prepared by centrifugation and stored frozen $\left(-20^{\circ} \mathrm{C}\right)$ until extracted on Sep-Pak columns as described above.
Fetal urine was obtained from five animals (mean gestational age $=126 \mathrm{~d}$ ) with chronic bladder catheters (21). Urine was collected during a 40-min equilibration period in which the fetal bladder catheter was allowed to drain to gravity. Urine was then collected for $1 \mathrm{~h}$, and aliquots were assayed directly for AVT, AVP, and OT immunoreactivity.

HPLC. The HPLC system consisted of two pumps (model 110A; Altex Scientific, Inc., Berkeley, CA), a solvent programmer (model 421; Beckman Instruments, Inc., Fullerton, $C A$ ), an injector (model 70-11; Rheodyne, Inc., Cotati, CA), and a $\mathrm{C}^{18} \mu$-Bondapak $(3.9 \times 30$ $\mathrm{cm}$ ) reversed-phase column (Waters Associates, Millipore Corp.). Solvent A was $0.1 \%$ trifluoroacetic acid (TFA; Pierce Chemical Co.); solvent B was $0.1 \%$ TFA in $80 \%$ acetonitrile $\left(\mathrm{CH}_{3} \mathrm{CN}\right)$. A linear gradient of increasing acetonitrile $(15-30 \%$ over $20 \mathrm{~min})$ was formed from a mixture of solvents A and B, controlled by the solvent programmer. HPLC grade water and acetonitrile were obtained from Fisher Scientific Co., Allied Corp., Pittsburgh, PA. All buffers were degassed before use.

Prepared pools of amniotic fluid, fetal urine, and fetal plasma were extracted as described above with Sep-Pak columns, and the AVP, AVT, and OT immunoreactivities of the respective pools were quantified. Extracts of fetal plasma, urine, or amniotic fluid were dissolved in sufficient volumes of $0.1 \%$ TFA to yield solutions of $\sim 100 \mathrm{pg} / \mathrm{ml}$ of AVT-like immunoreactivity (irAVT). Extracts in $0.1 \%$ TFA were filtered through $0.22-\mu \mathrm{M}$ filters (type GS; Millipore/Continental Water Systems, Bedford, MA), and the AVT, AVP, and OT immunoreactivities were determined before injection on the HPLC column.

Typically, $10 \mathrm{pg}$ of the synthetic standards (also in $0.1 \%$ TFA) or 5-10 pg of irAVT in the respective extracts was individually injected and the HPLC column eluted at ambient temperature. Standards were run on the same day that unknown samples were analyzed. Fractions of $750 \mu \mathrm{l}$ were collected, dried in a Speedvac concentrator, and assayed directly by RIA after the addition of assay buffer $(250 \mu \mathrm{l})$. Retention times were determined by the concentrations of either AVT, AVP, or OT immunoreactivity in each fraction.

Statistics. Hormone concentrations in the biological fluids studied are expressed as mean \pm SEM. AVT, AVP, and OT levels in each of the respective fluids (fetal plasma, urine, and amniotic fluid) were compared by the paired sample $t$ test. Differences between means were considered significant when $P<0.05$.

\section{Results}

Radioimmunoassay. Percent cross-reactivity and $B_{50}$ values for the AVT-Ab, AVP-Ab, and OT-Ab antisera with synthetic AVT, AVP, OT, MT, IT, LVP, and LVT are summarized in Table I. Cross-reaction of AVP-Ab with AVT was $0.08 \%$, and with OT $<0.01 \%$. The LVP cross-reaction was $33.4 \%$, and IT $0.08 \%$; LVT and MT cross-reacted at $<0.01 \%$. Cross-reactions of AVP or AVT with the OT-Ab were $0.27 \%$ and $0.1 \%$, respectively. MT exhibited a cross-reaction of only $1.0 \%$; LVT, LVP, and IT also were minimally reactive $(0.13 \%, 0.17 \%$, and $0.23 \%$, respectively). The AVT-Ab exhibited low level crossreactivity with AVP $(0.75-0.76 \%)$ and OT $(3.1 \%)$. MT crossreaction was similar to that observed with OT $(3.48-3.54 \%)$; LVT cross-reacted at $1.31-1.82 \%$. LVP and IT were nonreactive.

$A V T$ extraction method. The mean recovery of synthetic AVT from human or ovine plasma was $65 \pm 1 \%$ after the addition of $5,10,50$, or $100 \mathrm{pg} / \mathrm{ml}$ of peptide $(n=51)$. AVT added to human plasma before extraction diluted in a similar manner to standard AVT.

Fetal plasma, urine, and amniotic fluid $A V T, A V P$, and OT by RIA. Immunoreactive AVT, AVP, and OT levels observed in unstressed ovine fetal plasma, fetal urine, and amniotic fluid are summarized in Table II. Mean \pm SEM fetal plasma levels of AVT $(2.4 \pm 0.2 \mathrm{pg} / \mathrm{ml}), \operatorname{AVP}(3.8 \pm 1.0 \mathrm{pg} / \mathrm{ml})$, and OT $(2.7 \pm 0.4 \mathrm{pg} / \mathrm{ml})$ were similar. Urine AVT $(1.4 \pm 0.2$ 
Table I. AVT-Ab, AVP-Ab, and OT-Ab Cross-reactivity (CR) Studies

\begin{tabular}{|c|c|c|c|c|c|c|}
\hline \multirow[b]{2}{*}{ Synthetic peptide } & \multicolumn{2}{|l|}{ AVT-Ab } & \multicolumn{2}{|l|}{ AVP-Ab } & \multicolumn{2}{|l|}{ OT-Ab } \\
\hline & $B_{50}{ }^{*}$ & Percentage CR & $B_{50}$ & Percentage CR & $B_{50}$ & Percentage CR \\
\hline & $p g$ & & $p g$ & & $p g$ & \\
\hline AVT & 0.46 & 100 & 1,470 & 0.08 & 3,085 & 0.1 \\
\hline AVP & 61 & 0.75 & 1.15 & 100 & 1,115 & 0.27 \\
\hline OT & 14 & 3.07 & $>10,000$ & $<0.01$ & 2.97 & 100 \\
\hline LVT & 35 & 1.31 & 7,852 & $<0.015$ & 2,336 & 0.13 \\
\hline LVP & 6,783 & 0.0068 & 3.44 & 33.4 & 1,719 & 0.17 \\
\hline MT & 13 & 3.54 & $>10,000$ & $<0.01$ & 473 & 0.63 \\
\hline IT & $>10,000$ & $<0.0046$ & 1,469 & 0.08 & 1,275 & 0.23 \\
\hline
\end{tabular}

* $B_{50}$ values represent the mass of peptide producing $50 \%$ displacement of labeled ligand in the indicated RIA system.

$\mathrm{pg} / \mathrm{ml})$ was significantly $(P<0.05)$ less than AVP $(5.4 \pm 0.6$ $\mathrm{pg} / \mathrm{ml})$ and OT $(3.0 \pm 0.1 \mathrm{pg} / \mathrm{ml})$ levels observed; the AVP and OT levels were not different. Although the AVT and AVP levels in amniotic fluid were also similar $(1.9 \pm 0.2$ and $1.4 \pm 0.2$ $\mathrm{pg} / \mathrm{ml}$, respectively), the OT concentration was significantly $(P<0.05)$ higher $(10.3 \pm 2.5 \mathrm{pg} / \mathrm{ml})$.

HPLC. The HPLC elution profiles for synthetic AVT, AVP, and OT are shown in Fig. 1. 74\% of the applied AVT eluted from the column at $7.5 \mathrm{~min}$. The AVP standard eluted at $10.5 \mathrm{~min}$ with $98 \%$ recovery of the applied peptide. Oxytocin, the most hydrophobic of the three nonapeptides, eluted 15 min after injection; recovery of standard OT was never $<82 \%$.

Application of $100 \mu \mathrm{l}$ of an extract of ovine amniotic fluid to the HPLC column resulted in a single peak of irAVT that coeluted with synthetic AVT and was well separated from the small peak of apparent AVP cross-reactivity (Fig. 2). Because the peak of irAVT coeluting with synthetic AVT was reproducible and the small peak coeluting with AVP was not, the latter was discounted as an isolated fluctuation in the RIA baseline. The HPLC elution profile of irAVT isolated from an extract of ovine fetal urine is shown in Fig. 3. 74\% of the irAVT coeluted from the column with synthetic AVT and again was clearly separated from the smaller peak of immunoreactivity coeluting with synthetic AVP.

Application of an extract of an ovine fetal plasma pool to the HPLC column revealed two primary peaks of irAVT (Fig. 4). Peak I co-migrated with synthetic AVT while peak II eluted from the HPLC column with standard AVP. Phlebotomy is a well characterized stimulus of AVP secretion $(15,23)$, and the plasma pool used for HPLC analysis contained very high AVP $(>90 \mathrm{pg} / \mathrm{ml})$ and OT $(58 \mathrm{pg} / \mathrm{ml})$ concentrations. As a result,

Table II. AVT, AVP, and OT Immunoreactivities in Ovine Fetal Plasma, Urine, and Amniotic Fluid

\begin{tabular}{llll}
\hline & AVT & AVP & \multicolumn{1}{l}{ OT } \\
\hline & $p g / m l$ & $p g / m l$ & $p g / m l$ \\
Plasma (8) & $2.42 \pm 0.15$ & $3.83 \pm 1.02$ & $2.67 \pm 0.37$ \\
Urine (5) & $1.44 \pm 0.18$ & $5.36 \pm 0.55$ & $3.02 \pm 0.09$ \\
Amniotic fluid (8) & $1.92 \pm 0.16$ & $1.40 \pm 0.18$ & $10.31 \pm 2.48$
\end{tabular}

Hormone concentrations are expressed as the mean $\pm \mathrm{SEM}$; values in parenthesis indicate the number of animals in each group. the AVP $(9.9 \mathrm{ng} / \mathrm{ml})$ and OT $(278 \mathrm{pg} / \mathrm{ml})$ concentrations in the final concentrated plasma extract were much greater than the irAVT concentration $(104 \mathrm{pg} / \mathrm{ml})$. Thus, even though AVT-Ab cross-reaction with AVT is $<0.1 \%$ (Table I), the AVP levels were elevated sufficiently to yield a second significant peak of irAVT. A small peak of immunoreactivity coeluting with synthetic OT and some unidentified pre-OT immunoreactivity (tubes 24-27) were also observed. To confirm that peak I was native AVT, the apparent AVT peaks from several applications of fetal plasma extract to the HPLC column (the peak I fractions) were collected, combined, and rechromatographed. This yielded a single peak of irAVT that co-chromatographed with synthetic AVT and was not immunoreactive with either AVP-Ab or OT-Ab (Fig. 5).

\section{Discussion}

Because AVT is a structural hybrid of AVP and OT, the verification of this peptide in mammals has been difficult. AVT measured by bioassay has been reported in the neuro-

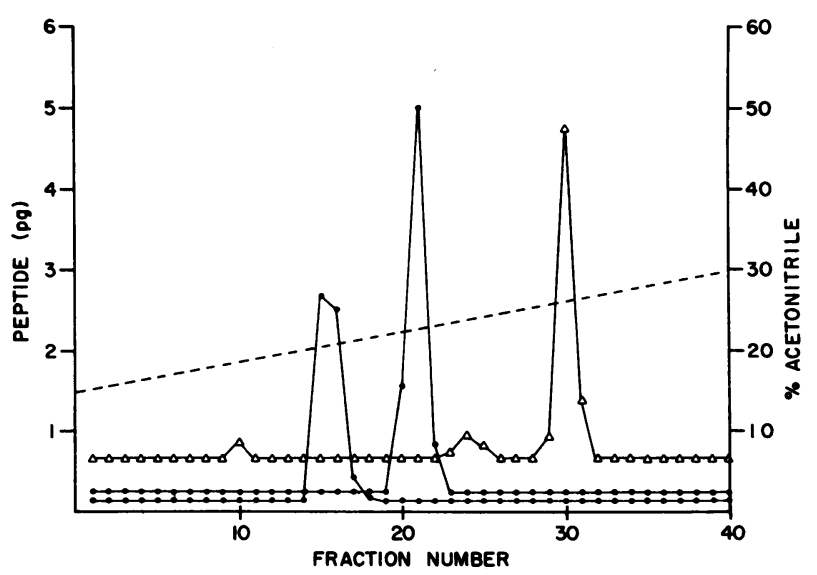

Figure 1. HPLC elution profile of synthetic AVT (๑), AVP (0), and OT $(\Delta)$. The column was equilibrated in $15 \%$ acetonitrile $(--)$ and $0.1 \%$ TFA and subsequently eluted with a linear acetonitrile gradient (15-30\%) over $20 \mathrm{~min}$ at a flow rate of $1.5 \mathrm{ml} / \mathrm{min} .10 \mathrm{pg}$ of each of the peptide standards was injected individually and fractions collected every $30 \mathrm{~s}$. The elution pattern was determined by assaying each fraction for either AVT-Ab, AVP-Ab, or OT-Ab immunoreactivity. 


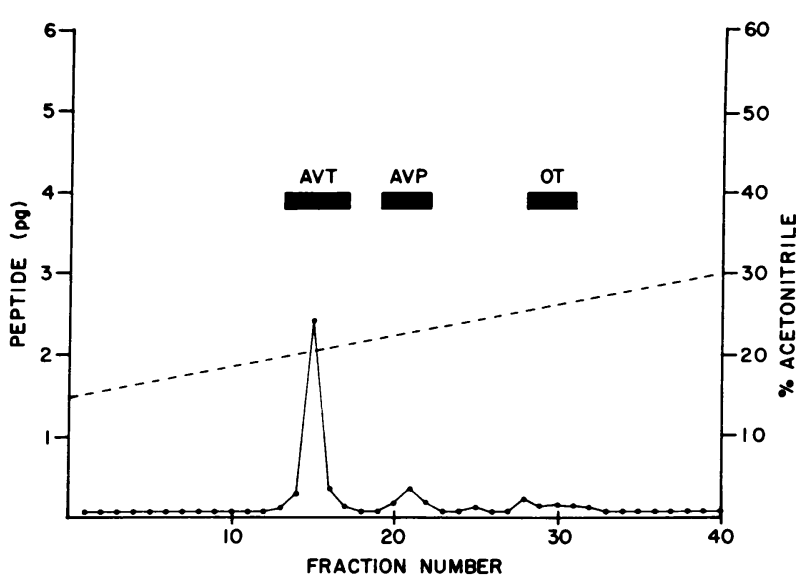

Figure 2. HPLC elution profile of an AVT-Ab immunoreactive material extracted from ovine amniotic fluid. The conditions for the HPLC analysis are the same as outlined in the legend for Fig. 1. The irAVT peak coeluted from the HPLC column with synthetic AVT and was well separated from both AVP and OT. The corresponding elution pattern of synthetic AVT, AVP, and OT standards is shown by the horizontal bars in the upper portion of the chromatogram. (---), Percentage acetonitrile.

hypophysis of mid-term fetal sheep (4), and cultured human fetal neurohypophysial cells have been reported to synthesize AVT (5). In studies using both RIA and HPLC methodology, AVT recently has been identified in the neurohypophysis of mid-term human fetuses (24). Although AVT has also been reported in human newborn cerebrospinal fluid $(18,25)$, the presence of AVT in mammalian circulation has not been investigated. In this study highly sensitive RIA and HPLCRIA systems were used in the quantification and characterization of irAVT in various biological fluids of fetal sheep. The results indicate the presence of native AVT in fetal plasma as well as fetal urine and amniotic fluid.

AVT and OT possess identical "ring" structures and differ only in having an arginine and leucine residue, respectively,

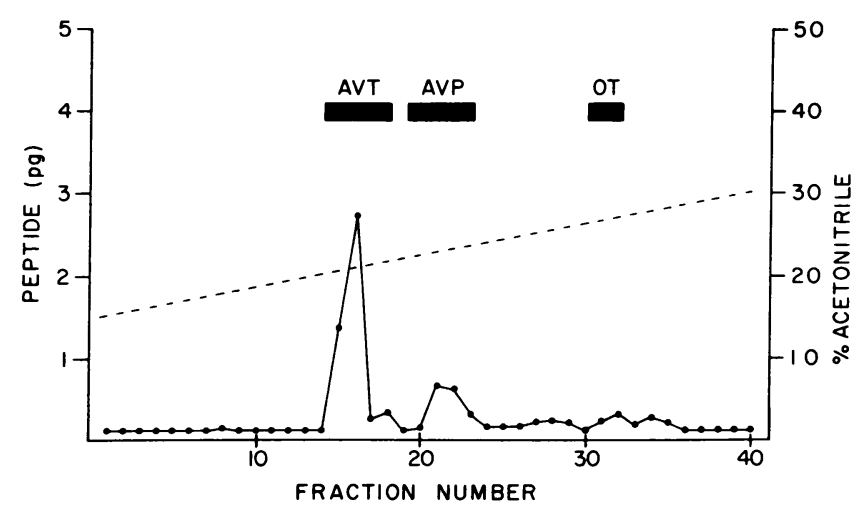

Figure 3. HPLC elution profile of an AVT-Ab immunoreactive material extracted from ovine fetal urine obtained in vivo. The conditions for the HPLC analysis are the same as outlined in the legend for Fig. $1.74 \%$ of the AVT-Ab immunoreactivity appeared as a single peak that coeluted with synthetic AVT, and was well separated from the small peak of AVP cross-reaction. The elution profile of the synthetic AVT, AVP, and OT standards is indicated by horizontal bars in the upper portion of the chromatogram. (---), Percentage acetonitrile.

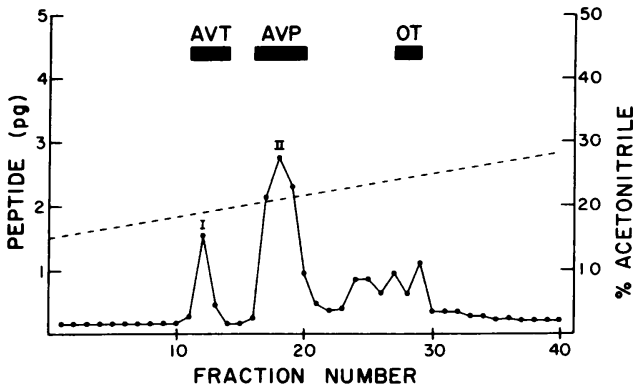

Figure 4. HPLC elution profile of AVT-Ab immunoreactivity extracted from ovine fetal plasma. The conditions for the HPLC analysis are the same as described in the legend for Fig. 1. In addition to two primary peaks of AVT-Ab immunoreactivity (I and II), several pre-OT immunoreactive peaks and a small peak of immunoreactivity in the vicinity of standard OT were observed. Peak I coeluted with synthetic AVT. Peak II eluted with standard AVP. Because the plasma pool used for the HPLC analysis contained elevated AVP levels, peak II is explained on the basis of AVT-Ab cross-reaction with AVP. The elution profile of the synthetic AVT, AVP, and OT standards is indicated by horizontal bars in the upper portion of the chromatogram. (-- ), Percentage acetonitrile.

in the number eight position of the "tail" of the molecule. The structures of AVP and AVT also are very similar, differing only in the substitution of phenylalanine for isoleucine in the number three position of the ring. Although AVP, AVT, and OT are structurally very similar, the combined application of the antisera in these studies (AVP-Ab, AVT-Ab, and OT-Ab) allowed clear discrimination among the peptides (Table I). The specificity of the antisera in recognition of the respective intact peptides is demonstrated by the fact that enzymatic

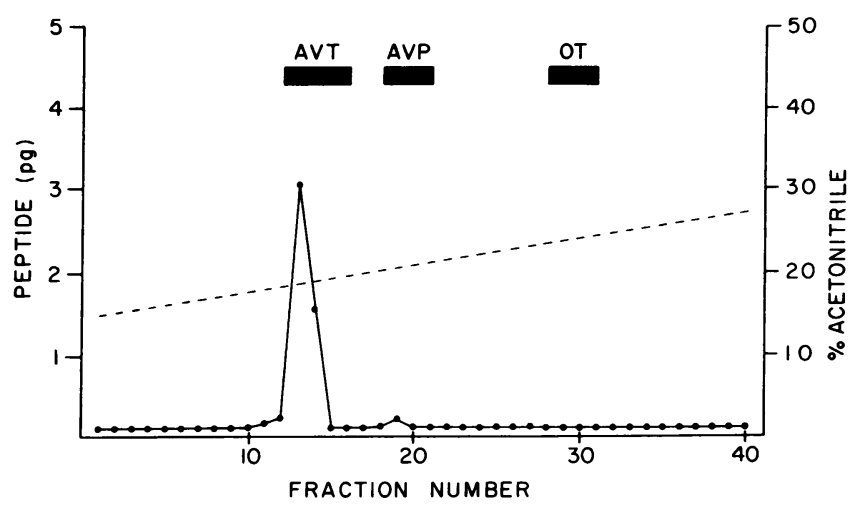

Figure 5. HPLC elution profile of an AVT-Ab immunoreactive material isolated from an extract of ovine fetal plasma. The elution profile of the synthetic AVT, AVP, and OT standards is indicated by horizontal bars in the upper portion of the chromotograph. To confirm the identity of the AVT-Ab immunoreactivity eluting as peak I from ovine fetal plasma (Fig. 4), six 100- $\mu$ l volumes of the plasma extract were successively applied to the HPLC column and the respective fractions pooled. $750 \mu \mathrm{l}$ was removed from each pooled fraction and assayed for AVT-Ab immunoreactivity. Fractions 11,12 , and 13 of the remaining pools were combined, dried, and reconstituted in $0.1 \%$ TFA. This purified material coeluted from the HPLC column with synthetic AVT and was not immunoreactive with either AVP-Ab or OT-Ab. The HPLC conditions used are the same as outlined in the legend for Fig. 1. (--), Percentage acetonitrile. 
degradation (with cystineaminopeptidase of human pregnancy plasma or with trypsin) abolished immunoreactivity (data not shown). In addition, none of the antisera cross-react significantly with either the ring of OT (tocinamide [18]) or the tripeptide tail portion of AVP (18). Thus from the data in Table I, the irAVT observed in the present studies of ovine fetal plasma, urine, and amniotic fluid does not appear to be attributable to any of the known neurohypophysial hormones except AVT or to known degradation products.

The AVT-Ab immunoreactivity could conceivably be due to one or more intermediates in the processing of the OT and AVP prohormones (prepropressophysin and preprooxyphysin) to yield OT and AVP (i.e., OT or AVT-Gly, OT or AVP-GlyLys, and OT or AVP-Gly-Lys-Arg). However, these intermediates do not represent significant products of the neurosecretory cells releasing AVP and OT into the circulation. Moreover, from the cross-reactivity data in Table $I$, the cross-reaction of any of the biosynthetic intermediates listed above would be, at most, no greater than for AVP or OT.

The identity of the irAVT in fetal plasma was further verified by its separation from AVP and OT and its coelution with synthetic AVT by HPLC (Fig. 4). Although the HPLC examination of the extracted fetal plasma pool was complicated by the presence of very high levels of AVP and OT, this problem was attenuated by a second chromatographic step (Fig. 5); the chromatography of the AVT peak material again showed coelution with synthetic AVT, and this irAVT exhibited no AVP-Ab or OT-Ab immunoreactivity. Thus, the immunoreactivity data and the HPLC analysis strongly support the view that the material isolated from ovine biological fluids is native AVT.

A material other than AVT could exhibit both irAVT with the AVT-Ab and coelute with synthetic AVT by HPLC; however, this appears remote. The necessity for HPLC confirmation of neurohypophysial peptide immunoreactivity data is clearly demonstrated by the analysis of fetal plasma (Fig. 4). The majority of the irAVT observed was attributable to either AVT or to AVP and OT cross-reaction. However, a portion of the irAVT eluted as a pre-OT peak that was not related to any of the peptide standards studied (AVP, AVT, and OT). This irAVT remains to be identified.

The physiological significance of AVT in the ovine fetus is unclear. Neither AVP nor OT cross the ovine placenta (26, 27), suggesting that fetal plasma AVT is of fetal origin. Fetal urinary AVT presumably accounts, at least in part, for the AVT observed in amniotic fluid. Vizsolyi and Perks (4) proposed that AVT may contribute to maternal-fetal water balance, based upon in vitro experiments in which AVT and AVP were shown to slow or completely reverse fetal-maternal water flux across the guinea pig amnion. However, these experiments used pharmacological levels of AVT and AVP. We have been unable to confirm this effect in vivo in the sheep. AVP or AVT instilled into the amniotic fluid had no demonstrable effect upon either amniotic fluid volume or osmolality, either alone or when followed by an osmotic stimulus to the ewe (22). However, we have reported data suggesting that both peptides inhibit fetal-maternal placental water transfer in response to an osmotic stimulus to the ewe (28), and both peptides appear to reduce ovine fetal lung fluid production (29). In these latter studies, however, the AVT concentration studied exceeded the physiological concentrations presently reported.
There is no information regarding the presence of AVT receptors in the fetus. Since the antidiuretic potency of AVT is $\sim 50 \%$ that of AVP in standard bioassays (1), it is possible that AVT might act via binding to renal AVP receptors. Although AVT is also a potent pressor agent in all vertebrates studied to date, its role in the regulation of blood pressure appears to be minimal (30). Due to the hybrid structure of AVT, the OT-like potential of this peptide also is intriguing; AVT has $\sim 25 \%$ of the potency of OT in eliciting uterine contractions. However, there is little available evidence to suggest that AVT acts as a physiological oxytocic agent in mammals.

In summary, we have shown that ovine fetal plasma contained measurable quantities of a material that is reactive with a specific AVT antiserum and coeluted from a reversedphase HPLC column with synthetic AVT. Further, this material that co-migrates with AVT by HPLC was not immunoreactive with antisera specific for either AVP or OT. Differential antineurohypophysial peptide antisera cross-reactivity studies suggest that this ovine AVT-like material is structurally similar to AVT. We conclude that intact AVT is present in ovine fetal plasma; however, the significance of mammalian AVT remains to be defined.

\section{Acknowledgments}

The authors are indebted to Ms. Linda Murray for her diligence in the preparation of the manuscript and to Mr. Jim Humme for his technical assistance.

These studies were supported in part by grants HD-06335 and HD-07013 from the National Institute of Child Health and Human Development, National Institutes of Health, Bethesda, MD.

\section{References}

1. Pliska, V. 1982. Phylogeny of neurohypophyseal hormones: parsimonial phylogenetic trees and evolution of some biological activities. In Neuroendocrinology of vasopressin, corticoliberin and opiomelanocortins. A. J. Baertschi and J. J. Driefuss, editors. Academic Press, New York. 177-189.

2. Acher, R. 1974. Chemistry of the neurohypophyseal hormones: an example of molecular evolution. In Handbook of Physiology, Vol. IV. E. Knobil and W. H. Sawyer, editors. American Physiological Society, Washington DC. 119-130.

3. Chauvet, M. T., D. Hurpet, J. Chauvet, and R. Acher. 1980. Phenypressin ( $\mathrm{Phe}^{2}-\mathrm{Arg}^{8}$-vasopressin), a new neurohypophyseal peptide found in marsupials. Nature (Lond.). 287:640-642.

4. Vizsolyi, E., and A. M. Perks. 1969. New neurohypophysial principle in fetal mammals. Nature (Lond.). 223:1169-1171.

5. Pavel, S. 1975. Vasotocin biosynthesis by neurohypophysial cells from human fetuses. Evidence for its ependymal origin. Neuroendocrinology. 19:150-159.

6. Ishikawa, H., and O. Nakamoto. 1981. Arginine vasotocin (AVT) immunoreactivity in hypothalamo-hypophyseal and pinealneurosecretory system in female baboon. Jikeikai Med. J. 28:85-99.

7. Pavel, S., R. Goldstein, and M. Calb. 1975. Vasotocin content in the pineal gland of fetal, newborn and adult male rats. J. Endocrinol. 66:283-284

8. Cheesman, D. W., and B. I. Fariss. 1970. Isolation and characterization of a gonadotrophin-inhibiting substance from the bovine pineal gland. Proc. Soc. Exp. Biol. Med. 133:1254-1256.

9. Rosenbloom, A. A., and D. A. Fisher. 1974. Radioimmunoassay of arginine vasotocin. Endocrinology. 95:1726-1732.

10. Dogterom, J., F. G. M. Snijdewint, P. Pevet, and D. F. Swaab. 1980. Studies on the presence of vasopressin, oxytocin and vasotocin 
in the pineal gland, subcommissural organ and fetal pituitary gland: failure to demonstrate vasotocin in mammals. J. Endocrinol. 84:115123.

11. Gauquelin, G., G. Geelen, A. M. Allevard-Burguburu, M. Cellier, B. Sempore, F. Louis, J. J. Legros, and C. Gharib. 1982. Presence of neurophysins I and II in human pineal gland: comparison with the content of neurohypophyseal hormones. Peptides (NY). 3: 805-809.

12. Fernstrom, J. D., L. A. Fisher, B. M. Cusack, and M. A. Gillis. 1980. Radioimmunologic detection and measurement of nonapeptides in the pineal gland. Endocrinology. 106:243-251.

13. Geelen, G., A. M. Allevard-Burguburu, G. Gauquelin, Y. Z. Xiao, J. Frutoso, and C. Gharib. 1981. Radioimmunoassay of argininevasopressin, oxytocin and arginine-vasotocin like material in the human pineal gland. Peptides (NY). 2:459-466.

14. Weitzman, R. E., and D. A. Fisher. 1978. Arginine vasopressin metabolism in dogs. I. Evidence for a receptor-mediated mechanism. Am. J. Physiol. 235:E591-E597.

15. Weitzman, R. E., T. H. Glatz, and D. A. Fisher. 1978. The effect of hemorrhage and hypertonic saline upon plasma oxytocin and arginine vasopressin in conscious dogs. Endocrinology. 103:2154-2160.

16. Skowsky, W. R., and D. A. Fisher. 1972. The use of thyroglobulin to induce antigenicity to small molecules. J. Lab. Clin. Med. 80:134144.

17. Weitzman, R. E., A. Reviczky, T. H. Oddie, and D. A. Fisher. 1980. Effect of osmolality on arginine vasopressin and renin release after hemorrhage. Am. J. Physiol. 238:E62-E68.

18. Artman, H. G., R. D. Leake, R. E. Weitzman, W. H. Sawyer, and D. A. Fisher. 1984. Radioimmunoassay of vasotocin, vasopressin and oxytocin in human neonatal cerebrospinal and amniotic fluid. Dev. Pharmacol. Ther. 7:39-49.

19. Skowsky, W. R., A. A. Rosenbloom, and D. A. Fisher. 1974. Radioimmunoassay measurement of arginine vasopressin in serum: development and application. J. Clin. Endocrinol. Metab. 38:278-287.

20. LaRochelle, F. T., Jr., W. G. North, and P. Stern. 1980. A new extraction of arginine vasopressin from blood: the use of octadecasilyl-silica. Pfluegers Arch. Eur. J. Physiol. 387:79-81.

21. Ross, M. G., M. G. Ervin, R. D. Leake, G. Oakes, C. Hobel, and D. A. Fisher. 1983. Bulk flow of amniotic fluid water in response to maternal osmotic challenge. Am. J. Obstet. Gynecol. 147:697-701.

22. Ervin, M. G., M. G. Ross, R. D. Leake, and D. A. Fisher. 1984. Arginine vasopressin plasma and urinary clearance in the fetal lamb. Am. J. Physiol. In press.

23. Alexander, D. P., H. G. Britton, M. L. Forsling, D. A. Nixon, and J. G. Ratcliffe. 1974. Pituitary and plasma concentrations of adrenocorticotropin, growth hormone, vasopressin and oxytocin in fetal and maternal sheep during the latter half of gestation and the response to hemorrhage. Biol. Neonate. 24:206-219.

24. Smith, A., and N. McIntosh. 1983. Neurohypophysial peptides in the human fetus: presence in pituitary extracts of immunoreactive arginine vasotocin. J. Endocrinol. 99:441-445.

25. Pavel, S. 1980. Presence of relatively high concentrations of arginine vasotocin in the cerebrospinal fluid of newborns and infants. J. Clin. Endocrinol. Metab. 50:271-273.

26. Glatz, T. H., R. E. Weitzman, P. W. Nathanielsz, and D. A. Fisher. 1980. Metabolic clearance rate and transplacental passage of oxytocin in the pregnant ewe and fetus. Endocrinology. 106:10061011.

27. Stegner, H., R. D. Leake, S. M. Palmer, A. M. Morris, and D. A. Fisher. 1984. Arginine vasopressin metabolic clearance and production rates in fetal sheep, lambs, maternal and nonpregnant adult sheep. Dev. Pharmacol. Ther. 7:87-93.

28. Leake, R. D., H. Stegner, S. M. Palmer, G. K. Oaks, and D. A. Fisher. 1983. Arginine vasopressin and arginine vasotocin inhibit ovine fetal/maternal water transfer. Pediatr. Res. 17:583-586.

29. Ross, M. G., M. G. Ervin, R. D. Leake, and D. A. Fisher. 1984. Fetal lung liquid regulation by neuropeptides. Am. J. Obstet. Gynecol. 150:421-425.

30. Pang, P. K. T., P. B. Furspan, and W. H. Sawyer. 1983. Evolution of neurohypophysial hormone actions in vertebrates. $\mathrm{Am}$. Zool. 23:655-662. 